\title{
Oxidation of gem-chloronitroso- and vic-chloronitroso-alkanes and -cycloalkanes to respective chloronitro compounds by novel cetyltrimethylammonium hypochlorite reagent ${ }^{\dagger}$
}

\author{
ABDULKARIM H A MOHAMMED ${ }^{\mathrm{a}, \mathrm{b}}$ and GOPALPUR NAGENDRAPPA ${ }^{\mathrm{a}, *}$ \\ ${ }^{a}$ Department of Chemistry, Bangalore University, (Central College Campus), Bangalore 560 001, India \\ 'University of Sana'a, Sana'a, Yemen \\ e-mail: gnagendrappa@gmail.com
}

MS received 28 November 2010; revised 23 April 2011; accepted 3 May 2011

\begin{abstract}
Cetyltrimethylammonium hypochlorite (CTAHC) is prepared and used as an oxidizing agent for nitroso group to nitro group. The gem-chloronitroso and vic-chloronitroso compounds are prepared respectively from ketoximes and olefins by reacting with $\mathrm{NOCl}$ generated in situ from chlorotrimethylsilane (TMSCl) and iso-amyl nitrite. CTAHC oxidizes gem-chloronitroso and vic-chloronitroso compounds to the corresponding chloronitro derivatives. While gem-chloronitro compounds are obtained in good yields, the vic-chloronitro derivatives are formed in moderate yields, because of the propensity of the vic-chloronitroso group to tautomerize to $\alpha$-chlorooxime. The present method is simple and practical, particularly for the preparation of vic-chloronitro compounds, considering the fact that the known methods of their preparation are few and quite involved.
\end{abstract}

Keywords. Cetyltrimethylammonium hypochlorite; oxidation; gem-chloronitroso compounds; vic-chloronitroso compounds; gem-chloronitro compounds; vic-chloronitro compounds; nitroso-to-nitro conversion; nitrosyl chloride; oxime.

\section{Introduction}

gem-Chloronitro-alkanes and -cycloalkanes are valuable starting compounds in organic synthesis. They are used to prepare nitroalkanes and nitrocycloalkanes ${ }^{1}$ by reductive dechlorination, ${ }^{2}$ and find other useful applications in organic synthetic procedures. ${ }^{3}$ They are generally prepared by the oxidation of the corresponding gem-chloronitroso compounds using oxidizing agents, such as ozone, ${ }^{4}$ oxone,${ }^{5}$ chlorotriazines, ${ }^{2 a}$ chloroperoxidases, ${ }^{6}$ peroxyacetic acid, ${ }^{2 b}$ trifluoroperoxyacetic acid, ${ }^{7}$ nitric acid, ${ }^{8}$ hydrogen peroxide, ${ }^{9} \mathrm{~N}$ bromosuccinimide, ${ }^{10}$ and sodium hypochlorite alone ${ }^{11}$ or with tetrabutylammonium hydrogen sulphate as phase transfer catalyst in a biphasic system. ${ }^{2 \mathrm{~d}}$ Recently, we have shown that nitryl chloride produced in situ oxidizes the nitroso group to nitro group. ${ }^{12}$

The required starting gem-chloronitroso compounds are prepared by the chlorination of oximes using elemental chlorine, ${ }^{13} t$-butylhypochlorite as well as hypochlorous acid, ${ }^{11,14} \mathrm{~N}$ - $t$-butyl-N-chlorocyanamide, ${ }^{15}$ hydrogen peroxide-hydrochlric acid, ${ }^{2 \mathrm{~b}} \mathrm{~N}$-chlorourea, ${ }^{16}$

${ }^{*}$ For correspondence

${ }^{\dagger}$ Extracted from the Ph D Thesis of AHAM. and N,N'-dichlorobis(2,4,6-trichlorophenyl)urea. ${ }^{17} \mathrm{Ni}$ trosyl chloride ${ }^{18}$ and nitryl chloride ${ }^{12}$ are found to be efficient reagents to convert oximes to gemchloronitroso compounds.

vic-Chloronitro compounds exhibit a variety of biological activities. ${ }^{19}$ They are found to act as insecticides ${ }^{20}$ fungicides, ${ }^{21}$ bactericides, ${ }^{22}$ miticides,${ }^{23}$ and herbicides. $^{21 \mathrm{~b}}$ Vinylic nitroolefins, obtained by the elimination of $\mathrm{HCl}$ from vic-chloronitro compounds, have been used as dienophiles in several synthetically useful Diels-Alder reactions, and undergo Michael addition with a variety of nucleophiles. ${ }^{1 \mathrm{~d}, 24 \mathrm{~d}, 25}$ In spite of their many applications, to our knowledge, there are only two methods of synthesis of vic-chloronitro compounds. One is by a free radical addition of $\mathrm{NO}_{2} \mathrm{Cl}$ or $\mathrm{N}_{2} \mathrm{O}_{4}{ }^{-}$ chlorine mixture with olefins, especially in the gas phase, which leads to a mixture of several nitration products including the vic-chloronitro derivatives. ${ }^{24}$ The second one is the addition of nitrosyl chloride to alkenes first to form vic-chloronitroso compounds, the latter are then allowed to stand for several days with excess nitrosyl chloride which slowly oxidizes them to vic-chloronitro derivatives. ${ }^{26}$ Both these methods pose problems of purification and give poor yields. 


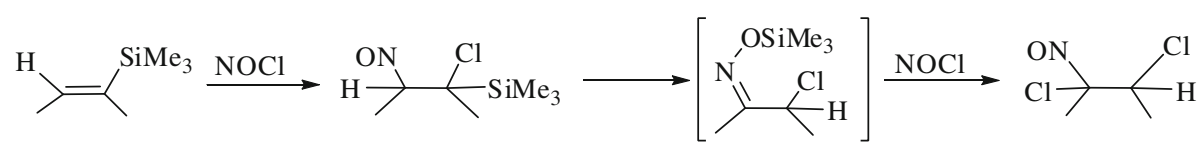

Scheme 1. Reaction of $\mathrm{NOCl}$ with vinylsilanes.

While $\mathrm{NOCl}$ reacts with oximes to produce gem-chloronitroso derivatives, it adds to alkenes and cycloalkenes to give vic-chloronitroso compounds. ${ }^{18 \mathrm{~b}, 27}$ We have shown earlier that NOCl, conveniently generated in situ by the reaction of amyl or iso-amyl nitrite with TMSCl under anhydrous conditions, brings about both these reactions in tandem in its reaction with vinylsilanes ${ }^{18 a, b}$ (scheme 1 ).

Since the methods employed for the oxidation of both gem- and vic-chloronitro compounds, especially the latter ones, are beset with deficiencies, we thought that introducing more efficient alternative routes for the preparation of chloronitrocycloalkanes and -alkanes would be useful.

We have developed cetyltrimethylammonium hypochlorite (CTAHC) as a novel oxidant for conversion of both gem- and vic-chloronitroso compounds to their corresponding chloronitro derivatives. This was formulated based on the fact that cetyltrimethylammonium group is an efficient and supportive countercation in such successful reagents as cetyltrimethylammonium permanganate $(\mathrm{CTAP})^{28}$ and dichromate (CTAD), ${ }^{29}$ and that hypochlorite is a good oxidant for conversion of nitroso to nitro group. ${ }^{2 \mathrm{~d}, 11}$ We have prepared CTAHC and found it to be a handy, practical oxidizing agent in homogeneous organic solvent media for oxidizing both gem-chloronitroso and vic-chloronitroso compounds, prepared respectively by reacting oximes and olefins with $\mathrm{NOCl}$ generated in situ. ${ }^{18 \mathrm{a}, \mathrm{b}, \mathrm{g}}$ The results are reported here.

\section{Experimental}

\subsection{General}

The NMR spectra were recorded on a JEOL FX90Q or Bruker AC-250 instrument using $\mathrm{CDCl}_{3}$ as solvent and tetramethylsilane (TMS) as internal standard. The IR spectra were taken on Nicolet Impact 400D single beam instrument using $\mathrm{KBr}$ pellets for solids and thin film between $\mathrm{NaCl}$ plates for liquids. GC analyses were carried out on a Varian Vista 6000 instrument using 15\% of FFAP on chromosorb-W column $(2 \times 2 \mathrm{~mm}$ i.d. $)$. The solvents were distilled before use. Diethyl ether was washed with $10 \% \mathrm{FeSO}_{4}$ solution, dried over $\mathrm{CaCl}_{2}$, refluxed over sodium wire-benzophenone and distilled.
Silica gel (Qualigens) used for column chromatography (60-120 mesh size) was activated by heating to $110^{\circ} \mathrm{C}$ before use.

Cyclopentanone, cyclohexanone, cycloheptanone, cyclooctanone, cyclododecanone, norcamphor, and propiophenone were obtained from Aldrich Chemical Company. Acetophenone was obtained from SD Fine Chemicals. Dibenzyl ketone was prepared by the literature procedure. ${ }^{30 a}$ Hydroxylamine hydrochloride was of A.R. grade. The oximes were prepared following the known procedure. ${ }^{30 \mathrm{~b}}$

Cyclopentene, cyclohexene, cycloheptene and 1heptene were prepared by dehydration of the corresponding alcohols; (cyclopentanol and cycloheptanol were prepared by reducing cyclopentanone and cycloheptanone using sodium-wet ether). Cyclooctene, cyclododecene (cis-trans mixture) and norbornene were purchased from Aldrich. Chlorotrimethylsilane (TMSCl) and cetyltrimethylammonium bromide were purchased from Spectrochem, and TMSCl was distilled over quinoline (1-2\%). iso-Amyl nitrite was prepared by the literature procedure. ${ }^{30 \mathrm{c}}$ The liquid starting compounds obtained from commercial sources were distilled and their purity checked by G.C. before use.

\subsection{Preparation of cetyltrimethylammonium hypochlorite}

A solution of cetyltrimethylammonium bromide (CTAB, $21.0 \mathrm{~g}, 62.5 \mathrm{mmol}$ ) in $100 \mathrm{~mL}$ of dichloromethane was placed in a $1 \mathrm{~L} 2$-necked round bottomed flask equipped with a mechanical stirrer and a dropping funnel. Sodium hypochlorite solution $(120 \mathrm{~mL})$ containing $4 \%$ chlorine (only Merck company $\mathrm{NaOCl}$ worked well; $\mathrm{NaOCl}$ solution from other two commercial sources did not give CTAHC) was added over $5 \mathrm{~min}$. The mixture was stirred for 3-4 h; it was then transferred to a separating funnel and allowed to stand until the layers separated (there was frothing that took time to settle). The organic layer was collected, the solvent was removed on a rotary evaporator and the white residue was dried over $\mathrm{P}_{2} \mathrm{O}_{5}$ under vacuum, yield, $15.6 \mathrm{~g}(81 \%)$. It was recrystallised from hot ethyl acetate. It decomposed on heating above $200^{\circ} \mathrm{C}$ without melting, and was found to be soluble in chlorohydrocarbons and also water. 


\subsection{Synthesis of gem-chloronitroso compounds: General procedure}

A solution of $10 \mathrm{mmol}$ of oxime in $10 \mathrm{~mL}$ of dry diethyl ether was taken in a two-necked flask equipped with a short condenser fitted with a $\mathrm{CaCl}_{2}$ guard tube, and a dropping funnel. It was cooled to $-10^{\circ} \mathrm{C}$ with stir-

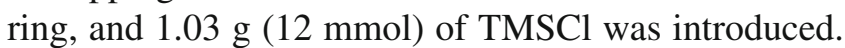
iso-Amyl nitrite $(1.40 \mathrm{~g}, 12 \mathrm{mmol})$ was added over a period of $15 \mathrm{~min}$. The reaction mixture was kept stirred for 1.0-2.5 h depending on the oxime (table 1), and as determined by TLC analysis. Water $(10 \mathrm{~mL})$ was added and the contents of the flask were transferred to a separating funnel (the flask was rinsed with $5 \mathrm{~mL}$ ether). The organic layer was separated and washed successively with water $(2 \times 15 \mathrm{~mL})$, saturated $\mathrm{NaCl}$ solution $(2 \times 15 \mathrm{~mL})$, and dried over $\mathrm{Na}_{2} \mathrm{SO}_{4}$. The solvent was removed on a rotary evaporator under reduced pressure and the residue was chromatographed on silica gel $\left(60-120\right.$ mesh) using petroleum ether (b.p. $50-55^{\circ} \mathrm{C}$ ) as eluant. The pure gem-chloronitroso products 1a-10a eluted as blue band. The compounds 5a, 6a, and 11a were solids, and were recrystallised from ethanol. The yields were 93-97\% (table 1). Their identity was established by comparing their spectral properties with those we reported previously in the case of the reaction of $\mathrm{NO}_{2} \mathrm{Cl}$ with the same oximes. ${ }^{12}$ We have reported the crystal structure the compound 5a. ${ }^{18 \mathrm{~d}}$

\subsection{Preparation of gem-chloronitro compounds: General procedure}

A solution of $10 \mathrm{mmol}$ of gem-chloronitroso compound in $10 \mathrm{~mL}$ of dichloromethane was placed in a $100 \mathrm{~mL}$ two-necked flask equipped with dropping funnel and a condenser fitted with a $\mathrm{CaCl}_{2}$ guard tube. A solution of $4.9 \mathrm{~g}(14 \mathrm{mmol})$ of CTAHC in $15 \mathrm{~mL}$ of dichloromethane was added over $15 \mathrm{~min}$. The mixture was stirred until the chloronitroso compound disappeared, as confirmed by GC analysis. The reaction needed 3-13 h for completion depending on the chloronitroso compound (table 2). The solvent was removed on a rotary evaporator under vacuum; the residue was dissolved in $50 \mathrm{~mL}$ of ether. The ensuing solution was washed with water $(30 \times 20 \mathrm{~mL})$ and saturated $\mathrm{NaCl}$ solution $(3 \times 20 \mathrm{~mL})$, and dried over $\mathrm{Na}_{2} \mathrm{SO}_{4}$. After removing the solvent the product was chromatographed on silica gel (60-120 mesh) using petroleum ether $\left(50-55^{\circ} \mathrm{C}\right)$ as eluant. The isolated yields of the gem-chloronitro compounds varied from 50-70\% (table 2).

\subsection{Oxime to gem-chloronitro compound: One-pot reaction}

In a $100 \mathrm{~mL}$ two-necked flask, equipped with a dropping funnel and condenser fitted with a $\mathrm{CaCl}_{2}$ guard tube, was placed $10 \mathrm{mmol}$ of oxime, $5 \mathrm{~mL}$ of dry ether was added and the solution was cooled to $-10^{\circ} \mathrm{C}$ with stirring. TMSCl (1.2 g, $13 \mathrm{mmol})$ was added dropwise, the solution was stirred for further 10-15 min, and then $1.4 \mathrm{~g}(12 \mathrm{mmol})$ of iso-amyl nitrite was added over 15-20 min. The reaction mixture was stirred for $1-2.5 \mathrm{~h}$ (as mentioned in table 1), and allowed to attain room temperature. To this was added a solution of $6.0 \mathrm{~g}$ $(17.8 \mathrm{mmol})$ of CTAHC in $25 \mathrm{~mL}$ of dichloromethane and the mixture was stirred until the chloronitroso compound disappeared (TLC analysis). The volatile substances were removed on a rotary evaporator under

Table 1. Preparation of gem-chloronitroso compounds form oximes and NOCl.

\begin{tabular}{|c|c|c|c|c|c|c|}
\hline Entry & Oxime of & gem-Chloronitroso Compds ${ }^{a}$ & & Reaction time (h) & Yield (\%) & m.p. $\left({ }^{\circ} \mathrm{C}\right)^{\mathrm{b}}$ \\
\hline 1 & Cyclopentanone & 1-Chloro-1-nitrosocyclopentane & (1a) & 1.5 & 93 & \\
\hline 2 & Cyclohexanone & 1-Chloro-1-nitrosocyclohexane & $(\mathbf{2 a})$ & 1.0 & 95 & \\
\hline 3 & Cycloheptanone & 1-Chloro-1-nitrosocycloheptane & $(3 \mathbf{a})$ & 1.5 & 95 & \\
\hline 4 & Cyclooctanone & 1-Chloro-1-nitrosocyclooctane & $(4 \mathbf{a})$ & 1.5 & 96 & \\
\hline 5 & Cyclododecanone & 1-Chloro-1-nitrosocyclododecane & $(\mathbf{5 a})$ & 1.5 & 98 & $50-52$ \\
\hline 6 & Norcamphor & 2-Chloro-2-nitrosonorbornane & $(\mathbf{6 a})$ & 1.0 & 98 & $42-44$ \\
\hline 7 & Acetophenone & 1-Chloro-1-nitroso-1-phenylethane & (7a) & 2.5 & 93 & \\
\hline 8 & Propiophenone & 1-Chloro-1-nitroso-1-phenylpropane & (8a) & 2.0 & 94 & \\
\hline 9 & 4-Heptanone & 4-Chloro-4-nitrosoheptane & $(9 a)$ & 1.0 & 96 & \\
\hline 10 & Dibenzoyl ketone & 2-Chloro-2nitroso-1,3-diphenylpropane & (10a) & 1.0 & 97 & $93-95$ \\
\hline
\end{tabular}

${ }^{a}$ We had earlier obtained the compounds $\mathbf{1 a}-\mathbf{1 0 a}$ by reacting oximes with $\mathrm{NO}_{2} \mathrm{Cl}^{12}$

${ }^{b}$ Except 5a, 6a, and 10a, the others are liquids, and decompose rapidly on heating 
Table 2. Oxidation of gem-chloronitroso to gem-chloronitro compounds by CTAHC.

\begin{tabular}{|c|c|c|c|c|c|c|}
\hline \multirow[t]{2}{*}{ Entry } & \multicolumn{2}{|l|}{ gem-Chloronitro compound } & \multicolumn{2}{|c|}{ From 1a-10a (Two steps) } & \multicolumn{2}{|c|}{ From 1a-10a (One-pot) } \\
\hline & & & Reaction time (h) & Yield (\%) & Reaction time (h) & Yield $(\%)$ \\
\hline 1 & 1-Chloro-1-nitrocyclopentane & (1b) & 13 & 70 & 16 & 72 \\
\hline 2 & 1-Chloro-1-nitrocyclohexane & $(2 b)$ & 13 & 74 & 16 & 77 \\
\hline 3 & 1-Chloro-1-nitrocycloheptane & $(3 b)$ & 12 & 70 & 14 & 71 \\
\hline 4 & 1-Chloro-1-nitrocyclooctane & $(4 b)$ & 13 & 68 & 15 & 73 \\
\hline 5 & 1-Chloro-1-nitrocyclododecane & $(5 b)$ & 4 & 70 & 5 & 78 \\
\hline 6 & 2-Chloro-2-nitronorbornane & $(6 \mathbf{b})$ & 10 & 70 & 13 & 75 \\
\hline 7 & 1-Chloro-1nitro-1-phenylethane & $(7 b)$ & 3 & 50 & 5 & 51 \\
\hline 8 & 1-Chloro-1-nitro-1-phenylpropane & $(8 b)$ & 3 & 50 & 5 & 53 \\
\hline 9 & 4-Chloro-4-nitroheptane & $(9 b)$ & 14 & 53 & 16 & 60 \\
\hline 10 & 2-Chloro-2-nitro-1,3-diphenylpropane & $(\mathbf{1 0 b})$ & 12 & 60 & 14 & 65 \\
\hline
\end{tabular}

vacuum, the residue was dissolved in $50 \mathrm{~mL}$ of ether, and the solution was washed with water $(3 \times 25 \mathrm{~mL})$, saturated $\mathrm{NaCl}(3 \times 20 \mathrm{~mL})$, and dried over $\mathrm{Na}_{2} \mathrm{SO}_{4}$. After removing the solvent, gem-chloronitro product was obtained as mentioned in the previous experiment. The yields were in the range of $51-78 \%$ (table 2).

\subsection{Preparation of vic-chloronitroso compounds: General procedure}

2.6a Method A-without solvent: In a $100 \mathrm{~mL}$ twonecked flask equipped with a dropping funnel and a condenser fitted with a guard tube were placed $10 \mathrm{mmol}$ of cycloalkene and cooled to $-10^{\circ} \mathrm{C}$. TMSCl was added drop-wise with stirring, followed by iso-amyl nitrite $(12 \mathrm{mmol})$ over a period of $20 \mathrm{~min}$. The reaction was followed by GC. The time taken for completion of the reaction varied widely depending on the cycloalkene, (table 3). When the cycloalkene had disappeared water $(10 \mathrm{~mL})$ was added, the white dimeric solid product was filtered off, washed with $10 \mathrm{~mL}$ of $10 \% \mathrm{NaHCO}_{3}$ solution, water $(10 \mathrm{~mL})$, and carefully with a little alcohol (under vacuum). The vic-chloronitroso compound was separated from the byproduct $\alpha$-chlorooxime by chromatographing on silica gel. (Eluant: petroleum ether, b.p. $50-55^{\circ} \mathrm{C}$, followed by $5 \%$ ethyl acetate in petroleum ether). The dimers were carefully (they are fairly soluble in ethanol) recrystallized from ethanol. We have reported the vic-chloronitroso compounds 11a-17a in an earlier paper, ${ }^{18 \mathrm{~g}}$ where the preparation method was slightly different.

2.6b Method B-in dichloromethane: The above reaction was conducted under the same conditions by taking the solution of cycloalkene in $10 \mathrm{~mL}$ of dry dichloromethane. At the end of the reaction, $10 \mathrm{~mL}$ of water was added, the layers were separated; organic layer was washed with water $(2 \times 15 \mathrm{~mL}), 10 \%$ $\mathrm{NaHCO}_{3}$ solution $(15 \mathrm{~mL})$, water $(15 \mathrm{~mL})$, saturated

Table 3. Preparation of vic-chloronitroso compounds by adding NOCl to olefins.

\begin{tabular}{|c|c|c|c|c|c|c|}
\hline \multirow[t]{2}{*}{ Entry } & \multicolumn{2}{|l|}{ vic-Chloronitroso compd ${ }^{\mathrm{a}}$} & \multicolumn{2}{|c|}{ Solvent-free reaction } & \multicolumn{2}{|c|}{ In $\mathrm{CH}_{2} \mathrm{Cl}_{2}$} \\
\hline & & & Reaction time (h) & Yield $(\%)^{\mathrm{a}}$ & Reaction time (h) & Yield $(\%)^{\mathrm{b}}$ \\
\hline 1 & 1-Chloro-2-nitrosocyclopentane & $(\mathbf{1 1 a})$ & 1.0 & $70(+20)$ & 1.5 & $60(+30)$ \\
\hline 2 & 1-Chloro-2-nitrosocyclohexane & $(\mathbf{1 2 a})$ & 1.5 & $65(+15)$ & 1.8 & $63(+30)$ \\
\hline 3 & 1-Chloro-2-nitrosocycloheptane & (13a) & 2.0 & $65(+13)$ & 2.5 & $60(+25)$ \\
\hline 4 & 1-Chloro-2-nitrosocyclooctane & (14a) & 2.5 & $60(+20)$ & 2.8 & $55(+25)$ \\
\hline 5 & 1-Chloro-2-nitrosocyclododecane & $(\mathbf{1 5 a})$ & 4.0 & $80(+10)$ & 4.0 & $70(+20)$ \\
\hline 6 & 2-Chloro-3-nitrosonorbornane & (16a) & 0.5 & $75(+10)$ & 0.5 & $70(+15)$ \\
\hline 7 & 2-Chloro-1-nitrosoheptane & $(\mathbf{1 7 a})$ & 3.0 & $57(+10)$ & 3.0 & $55(+15)$ \\
\hline
\end{tabular}

${ }^{\mathrm{a}}$ We have described the vic-chloronitroso compounds $11 \mathbf{a}-\mathbf{1 7 a}$ in an earlier paper ${ }^{18 \mathrm{~g}}$

${ }^{\mathrm{b}}$ Yield of the corresponding $\alpha$-chlorooxime, the product of tautomerisation 
Table 4. Oxidation of vic-chloronitroso to vic-chloronitro compounds.

\begin{tabular}{lllcl}
\hline Entry & \multicolumn{1}{c}{ Compound $^{\mathrm{a}}$} & & Reaction time (h) & Yield (\%) \\
\hline 1 & 1-Chloro-2-nitro-cyclopentane & $(\mathbf{1 1 b})$ & 12 & $40(+10)^{\mathrm{c}}$ \\
2 & 1-Chloro-2-nitro-cyclohexane & $\mathbf{( 1 2 b )}^{\mathrm{b}}$ & 15 & $35(+12)^{\mathrm{c}}$ \\
3 & 1-Chloro-2-nitro-cycloheptane & $(\mathbf{1 3 b})$ & 13 & $37(+10)^{\mathrm{c}}$ \\
4 & 1-Chloro-2-nitro-cyclooctane & $(\mathbf{1 4 b})$ & 10 & $30(+10)^{\mathrm{c}}$ \\
5 & 2-Chloro-3-nitro-norbornane & $\mathbf{( 1 6 b ) ~}^{\mathrm{b}}$ & 11 & $40(+15)^{\mathrm{c}}$ \\
6 & 2-Chloro-1-nitro-heptane & $\mathbf{( 1 7 b )}^{\mathrm{b}}$ & 10 & $35(+15)^{\mathrm{c}}$ \\
\hline
\end{tabular}

${ }^{a}$ 1-chloro-2-nitrosocyclododecane (15a) did not get oxidized

${ }^{\mathrm{b}} \mathbf{1 2 b},{ }^{31 \mathrm{a}} \mathbf{1 6}^{31 \mathrm{~b}}$ and $\mathbf{1 7 \mathbf { b } ^ { 3 1 \mathrm { c } }}$ are known in the literature; the other three are not

${ }^{\mathrm{c}}$ The numbers in parentheses are yields of the respective $\alpha$-chlorooximes

$\mathrm{NaCl}$ solution $(15 \mathrm{~mL})$, and dried over $\mathrm{Na}_{2} \mathrm{SO}_{4}$. In this case the byproduct $\alpha$-chlrooxime was formed in slightly higher proportion than in the previous case, and was separated by chromatography as in the previous experiment, (table 3 ).

\subsection{Oxidation of vic-chloronitroso to vic-chloronitro compounds}

A solution of $4.2 \mathrm{~g}(12 \mathrm{mmol})$ of CTAHC in $10 \mathrm{~mL}$ of $\mathrm{CH}_{2} \mathrm{Cl}_{2}$ was added to a solution of $10 \mathrm{mmol}$ of vicchloronitroso compound in $10 \mathrm{~mL}$ of $\mathrm{CH}_{2} \mathrm{Cl}_{2}$ stirred vigorously in a $100 \mathrm{~mL}$ two-necked flask equipped with a dropping funnel and a condenser fitted with a $\mathrm{CaCl}_{2}$ guard tube. The reaction mixture was kept stirred until the starting compound had disappeared, which took $10-15 \mathrm{~h}$ depending on the starting compound. All the vic-chloronitroso compounds, except 1chloro-2-nitrosocyclododecane, underwent oxidation. The solvent was removed on a rotary evaporator, the residue was dissolved in $50 \mathrm{~mL}$ of diethyl ether, and the resulting solution was washed with water $(2 \times 30 \mathrm{~mL})$, saturated $\mathrm{NaCl}$ solution $(2 \times 20 \mathrm{~mL})$, and dried over $\mathrm{Na}_{2} \mathrm{SO}_{4}$. After removing the solvent, the residue was chromatographed on a silica gel column using petroleum ether (b.p. $50-55^{\circ} \mathrm{C}$ ) as eluant. The yields of vic-chloronitro derivatives are modest, as $\alpha$-chlorooxime was formed as a by-product in each case (table 4). The spectral data of vic-chloronitro compounds are recorded in table 5.

Table 5. IR, ${ }^{1} \mathrm{H}$ NMR and ${ }^{13} \mathrm{C}$ NMR spectral data for vic-chloronitro compounds.

\begin{tabular}{llll}
\hline Compd & IR (neat), $v\left(\mathrm{~cm}^{-1}\right)($ selected $)$ & ${ }^{1} \mathrm{H} \mathrm{NMR}\left(\mathrm{CDCl}_{3}\right) \delta(\mathrm{ppm})$ & ${ }^{13} \mathrm{C} \mathrm{NMR}\left(\mathrm{CDCl}_{3}\right) \delta(\mathrm{ppm})$ \\
\hline $\mathbf{1 1 b}$ & $2976,2903,1564,1471$, & $4.532(\mathrm{~m}, 1 \mathrm{H})$, & $19.13,32.07,35.25$, \\
& $1440,1140,1357,1140$, & $3.079(\mathrm{~m}, 1 \mathrm{H})$, & $65.17,107.01$ \\
$\mathbf{1 2 b}$ & $1078,964,788,648$ & $1.94-2.644(\mathrm{~m}, 6 \mathrm{H})$, & $17.84,21.81,29.77,30.73$, \\
& $2955,2878,1569,1455$, & $4.76(\mathrm{~m}, 1 \mathrm{H})$, & $60.21,101.73$ \\
13b & $1440,1372,1191,1000$, & $2.56-2.66(\mathrm{~m}, 1 \mathrm{H})$, & \\
& $984,866,762,695,545$ & $1.52-2.43(\mathrm{~m}, 8 \mathrm{H})$ & $20.74,21.00,25.10$, \\
& $2966,2929,2857,1564$, & $4.85(\mathrm{~m}, 1 \mathrm{H})$, & $29.26,34.90$, \\
14b & $1481,1450,1362,1134$, & $2.49-2.68(\mathrm{~m}, 1 \mathrm{H})$, & $64.87,107.77$ \\
& $1072,814,788,643$ & $1.522-2.37(\mathrm{~m}, 10 \mathrm{H})$ & $21.81,24.59,25.31$, \\
& $2929,2862,1636,1564$, & $5.15-5.30(\mathrm{~m}, 1 \mathrm{H})$, & $25.96,30.72,32.80$, \\
16b & $1466,1460,1352,1222$, & $2.84-2.97(\mathrm{~m}, 1 \mathrm{H})$, & $57.63,103.74$ \\
& $1186,1021,881,721,643$ & $2.55-1.51(\mathrm{~m}, 12 \mathrm{H})$ & $23.51,26.91,35.71$, \\
& $2981,2888,1693,1569$, & $4.95-4.92(\mathrm{~m}, 1 \mathrm{H})$, & $48.31,53.46,65.63$, \\
& $1455,1347,1316,995$, & $4.74-4.77(\mathrm{~m}, 1 \mathrm{H})$, & 105.52, and $23.46,26.57$, \\
17b & $953,850,819,772,736$ & $2.20-3.14(\mathrm{~m}, 3 \mathrm{H})$, & $36.07,47.98,52.90$, \\
& & $1.57-1.80(\mathrm{~m}, 6 \mathrm{H})$ & $64.22,105.52^{\mathrm{a}}$ \\
& & & $13.61,12.76,23.12$,
\end{tabular}

${ }^{a}$ Mixture of two isomers 


\section{Results and discussion}

\section{1 gem-Chloronitro compounds}

Cetyltrimethylammonium hypochlorite (CTAHC) was prepared by a procedure similar to the one used for the preparation of CTAP. ${ }^{28}$ When cetyltrimethylammonium bromide in dichloromethane and commercially available sodium hypochlorite solution are mixed and mechanically stirred at room temperature, they undergo double displacement, and CTAHC accumulates in the dichloromethane phase, which is separated and worked up to get the white solid. However, CTAHC is relatively more soluble in water than CTAP, hence needs more careful work-up. It decomposes without melting above $200^{\circ} \mathrm{C}$, but can be stored intact in refrigerator for several months.

$$
\begin{aligned}
& \mathrm{CH}_{3}-\left(\mathrm{CH}_{2}\right)_{15} \stackrel{+}{\mathrm{N}}\left(\mathrm{CH}_{3}\right)_{3} \stackrel{-}{\mathrm{Br}}\left(\mathrm{CH}_{2} \mathrm{Cl}_{2}\right)+\mathrm{NaOCl}(\mathrm{aq}) \\
& \longrightarrow \mathrm{CH}_{3}-\left(\mathrm{CH}_{2}\right)_{15} \stackrel{+}{\mathrm{N}}\left(\mathrm{CH}_{3}\right)_{3} \stackrel{-}{\mathrm{O} C l}\left(\mathrm{CH}_{2} \mathrm{Cl}_{2}\right)+\mathrm{NaBr}(\mathrm{aq})
\end{aligned}
$$

Ten ketoximes 1-10 were treated with TMSCl and iso-amyl nitrate at $-10^{\circ} \mathrm{C}$. The $\mathrm{NOCl}$ generated in situ reacted with oximes to produce the corresponding blue coloured gem-chloronitroso derivatives 1a-10a (scheme 2), which were obtained in pure form by passing through silica gel column in almost quantitative yield (table 1). They were identified by their spectral data as described in our previous paper. ${ }^{12} 1$ Chloro-1-nitrosocyclododecane (5a), 2-chloro-2nitrosonorbonane (6a) and 2-chloro-2-nitroso-1,3diphenylpropane (10a) are stable solids. We have earlier reported the crystal structure of the compound 5a. ${ }^{18 \mathrm{~d}}$ The others $(\mathbf{1 a - 4 a}$ and $\mathbf{7 a - 9 a})$ are liquids, which decompose slowly at room temperature, and rapidly on heating. Their blue colour indicates that they exist in monomeric form. The dimerisation, which is a common feature of nitroso compounds, ${ }^{18 \mathrm{a}, \mathrm{b}}$ is prevented because of electronegative effect and steric hindrance of the geminal chlorine group. In contrast, the vic-chloronitroso compounds dimerise ${ }^{18 \mathrm{~g}}$ easily (scheme 3).

The oxidation of gem-chloronitroso compounds 1a10a was carried out in dichloromethane at room temperature by using about a $40 \%$ excess of CTAH. The reaction takes $3-13 \mathrm{~h}$ for completion depending on the structure of the starting compound (table 2). The gemchloronitro derivatives $\mathbf{1 b} \mathbf{- 1 0 b}$ (scheme 2), after isolation by usual work-up and purification by chromatographing on silica gel, were identified by comparing their spectral data with those described previously. ${ }^{12}$
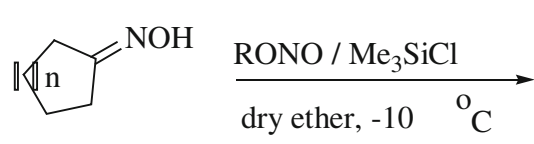<smiles>N#CC1(Cl)CCNC1</smiles><smiles>[H][Y13]1([AlH2])CCC(Cl)([N+](=O)[O-])C1</smiles>

1, $\mathrm{n}=1$

2, $\mathrm{n}=2$

3, $\mathrm{n}=3$

4, $\mathrm{n}=4$

5, $\mathrm{n}=8$<smiles>ON=C1CC2CCC1C2</smiles>

6<smiles>[R]C([R])=[NH2+]</smiles>

7, $\mathrm{R}^{1}=\mathrm{Ph}, \mathrm{R}^{2}=\mathrm{CH}_{3}$

8, $\mathrm{R}^{1}=\mathrm{Ph}, \mathrm{R}^{2}=\mathrm{C}_{2} \mathrm{H}_{5}$

9, $\mathrm{R}^{1}=\mathrm{R}^{2}=\mathrm{n}-\mathrm{C}_{3} \mathrm{H}_{7}$

10, $\mathrm{R}^{1}=\mathrm{R}^{2}=\mathrm{Ph}-\mathrm{CH}_{2}$
$1 a$

$2 \mathbf{a}$

$3 a$

4a

$5 \mathbf{a}$
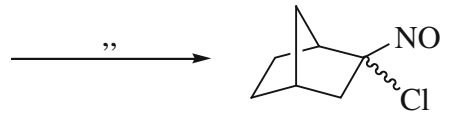

$6 a$

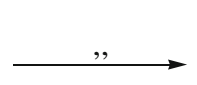

1b

2b

3b

$4 b$

$5 \mathbf{b}$
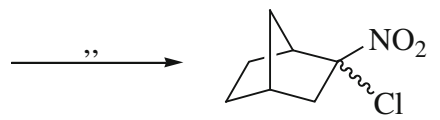

6b<smiles>[R]C([R])(Cl)[N+](=O)[O-]</smiles>

$7 \mathrm{~b}$

$8 b$

9b

$10 b$

Scheme 2. Preparation of gem-chloronitro compounds. 


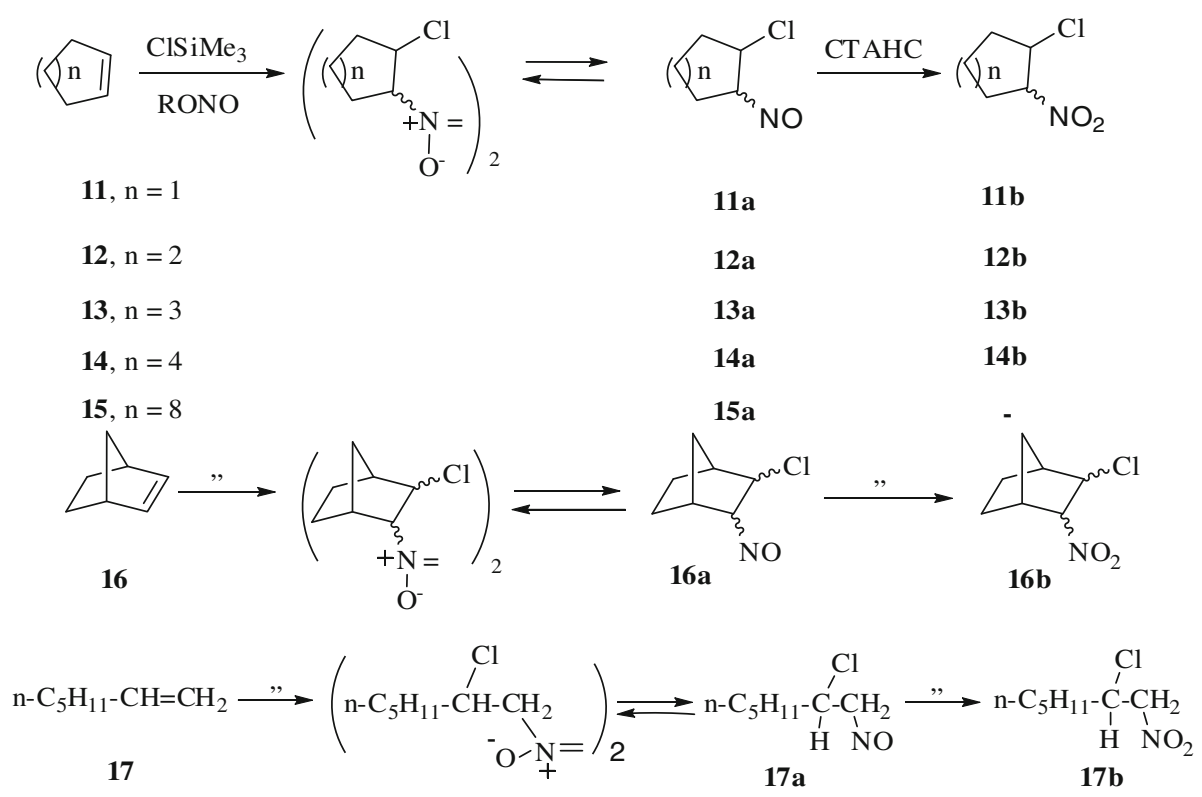

Scheme 3. Preparation of vic-chloronitro compounds.

\subsection{One-pot procedure for oxime to gem-chloronitro compound}

The oximes could also be converted to their respective gem-chloronitro derivatives by a one-pot process. In this method, each oxime in ether solution at $-10^{\circ} \mathrm{C}$ was first treated with TMSCl and iso-amyl nitrite to form gem-chloronitroso compound, after the mixture attained room temperature, it was treated with the required quantity of CTAHC in ether solution, stirred until the chloronitroso compound disappeared, and worked-up to get the gem-chloronitro derivative. The yields were slightly better (table 2) than in the case of the reactions carried out in two separate steps, which is attributable to single work-up step.

\section{3 vic-Chloronitro compounds}

Six vic-chloronitro compounds, 11b-14b, 16b and 17b were prepared by a two-step procedure. In the first step, vic-chloronitroso compounds 11a-17a were prepared by adding $\mathrm{NOCl}$, generated in situ, to cycloalkenes and alkenes 11-17 (scheme 3). While 1-chloro-2nitrosocycloheptane (13a) remained as blue monomer, the other adducts, 11a, 12a, and 14a-17a, were obtained as white dimeric diazine dioxide products, ${ }^{18 \mathrm{~g}}$ which exhibited widely varying stability. The dimer of 2-chloro-3-nitrosonorbornene (16a) is quite stable even in solution, whereas the other dimers dissociate into monomers in solution resulting in monomer-dimer equilibrium. ${ }^{18 \mathrm{~b}, \mathrm{~d}, \mathrm{~g}}$
The vic-chloronitroso compounds were treated at room temperature, with $20 \%$ excess of CTAHC. This produced 1-chloro-2-nitro compounds 11b-14b, 16b and $\mathbf{1 7 b}$, which were obtained after usual work-up and purification by chromatographing on silica gel column (table 4). They were identified by their spectral data (table 5). 1-Chloro-2-nitroso-cyclododecane (15a) did not undergo oxidation. The ${ }^{1} \mathrm{H}$ and ${ }^{13} \mathrm{C}$ NMR data (table 5) clearly indicated that each monocyclic vic-chloronitro derivative (11b-14b) was a single stereoisomer and most likely trans. However, 2-chloro-3-nitronorbornane was a mixture of a major and a minor component, the major one being the exo, cis derivative. ${ }^{18 \mathrm{a}, \mathrm{b}, 271}$ The chloronitroheptane (17b) contained $10-15 \%$ of probably a regioisomeric impurity. Three of these, i.e., 12b, $\mathbf{1 6 b}$ and $\mathbf{1 7 b}$ are known in the literature, while the other three are not.

The monomeric adducts with $\alpha$-hydrogen tend to tautomerise to give chlorooximes fairly rapidly particularly in the presence of acidic or basic impurities. $^{18 \mathrm{~g}}$ If excess $\mathrm{NOCl}$ is generated, the initially formed monomer produces $\alpha$-chlorooxime as intermediate which further reacts with $\mathrm{NOCl}$ to finally give 1,2-dichloro-1-nitroso derivatives. ${ }^{18 b}$ Actually, in these reactions some amount of $\alpha$-chlorooximino derivatives were isolated (table 4). Even during CTAH oxidation of the pure vic-chloronitroso compounds, some further quantity of chlorooxime was isolated as by-product in each case. As a result, the yields of vic-chloronitro derivatives were less than expected. 


\section{Conclusions}

The oxidation of 1-chloro-1-nitroso and 1-chloro2-nitroso compounds can be efficiently carried out using the novel cetyltrimethylammonium hypochlorite (CTAHC) reagent to the corresponding chloronitro derivatives. Considering the fact that CTAHC is easy to prepare and to handle, the method offers an easy access to the gem-chloronitro and vic-chloronitro compounds, which have many useful synthetic as well as other applications. The present method is promising particularly for the preparation of vic-chloronitro compounds, as the literature methods involve the complicated free radical reactions of $\mathrm{NO}_{2} \mathrm{Cl}$ or $\mathrm{N}_{2} \mathrm{O}_{4}+\mathrm{Cl}_{2}$ mixture with olefins, which require extensive purification and give low yields of the desired products.

\section{Acknowledgements}

AHAM thanks Indian Council for Cultural Relations (ICCR), NewDelhi, for a fellowship under Cultural Exchange Programme. The work was partly supported by UGC-DRS and UGC-COSIST programmes, NewDelhi. Some equipment used for the work is a donation to GN by the Alexander von Humboldt Foundation, Germany.

\section{References}

1. For a comprehensive account on nitroso and nitro compounds see, (a) Patai S (ed) 2003 The chemistry of amino, nitroso, and nitro compounds and related groups (Wiley-Interscience), (and its earlier editions); (b) Ono N 2001 Nitro group in organic synthesis (Wiley-VCH); (c) Feuer H and Nielsen A 1990 Nitrocompounds: recent advances in synthesis and chemistry (New York: $\mathrm{VCH}$ ); (d) Feuer H 1969 The chemistry of nitro and nitroso groups (New York: Interscience Publishers); (e) Agarwal J P and Hodgson R D 2007 Organic chemistry of explosives (John-Wiley); (f) Shvekhgeimer G A, Zvoliniskii V I and Kobrakou K I 1986 Chem. Hetero. Comp. 22353

2. (a) Walters T R, Zajac W W and Woods J M $1991 \mathrm{~J}$. Org. Chem. 56 316; (b) Terent'ev A O, Krylov I B, Ogibin Y N and Nikishin G I 2006, Synthesis 3819; (c) AmrollaMadjdabadi A, Beugelmans R and Lechevallier A 1986, Synthesis 826; (d) Corey E J and Estreicher H 1980, Tetrahedron Lett. 21 1117; (e) Sakai I, Kawabe N and Ono M 1979, Bull. Chem. Soc. Jpn. 523381

3. (a) Ono N, Tamura R, Hayami J-i and Kaji A 1977 , Chem. Lett. 189; (b) Russell G A, Mudryk B and Jawdosiuk M 1981 Synthesis 62; (c) Ono N, Tamura R, Eto H, Hamamoto I and Nakatsuka T 1983 J. Org. Chem. 48 3678; (d) Russell G A and Hershberger J 1980 J. Chem. Soc. Chem. Commun. 216; (e) Russell G A,
Mudryk B, Ros F and Jawdosiuk M 1982 Tetrahedron 38 1059; (f) Fridman A L, Surkov V D and Novikov S S 1980 Russ. Chem. Rev. 491068

4. Barnes M W and Patterson J M 1976 J. Org. Chem. 41 733

5. Ceccherelli P, Curini M, Epitano F, Marotullio M C and Rosati O 1998 Tetrahedron Lett. 394385

6. Zaks A, Yabannavar A V, Dodds D R, Evans C A, Das P R and Malchow R 1996 J. Org. Chem. 618692

7. (a) Marchand A P and Suri S C 1984 J. Org. Chem. 49 2041; (b) Nielsen A T 1962 J. Org. Chem. 27 1993; (c) Paquette L A, Fischer J. W and Engel P J 1985 J. Org. Chem. 50 2524; (d) Marchand A P and Reddy D S 1984 J. Org. Chem. 494078

8. Iffland D C and Criner G Y 1953 J. Am. Chem. Soc. 75, 4047

9. Paquette L A, Waykole L M and Shen C-e 1988 J. Org. Chem. 534969

10. (a) Marchand A P, Arney Jr B E and Dave P R 1988 J. Org Chem. 53 443; (b) Baum K and Archibald T G 1988 J. Org. Chem. 534645

11. (a) Archibald G A, Garver G, Baum K and Cohen M C 1989 J. Org. Chem. 54 2869; (b) Eiserich J P Cross C E, Jones A D, Halliwell B and van der Vliet A 1996 J. Biol. Chem. 27119199

12. Abdulkarim A H A and Nagendrappa G 2010 J. Chem. Sci. 122571

13. (a) Kresze G, Mayer N M and Winkler J 1971 Ann. Chem. 747 172; (b) Bosch T, Kresze G and Winkler J 1975 Ann. Chem. 1009; (c) Sakai I, Kawabe N and Ohno M 1979 Bull. Chem. Soc. Jpn. 52 3381; (d) Tordeux M, Boumizane K and Wakselman C 1995 J. Fluorine Chem. 70 207; (e) Müller E, Fries D and Metzger H 1955 Chem. Ber. 88 1891; (f) Mackor A and de Boer T J 1970 Recl. Trav. Chem. Pays-Bas 89 151; (g) Hammick D L and Lister M W 1937 J. Chem. Soc. 489

14. (a) Defoin A, Joubert M, Heuchel J M, Strehler C and Streith J 2000 Synthesis 1719; (b) Davis P, Vogt H C, Deck C F 1976 US Patent 3,960,822; (c) Diekmann H and Lüttke W 1968 Angew. Chem. Int. Ed. 7 387; (d) Nacef B, Daudon M and Pinatel H 1977 Synth. Commun. 7 153; (e) Nitsch H and Kresze G 1976 Angew. Chem. Int. Ed. 15 760; (f) Sabuni M, Kresze G and Braun H 1984 Tetrahedron Lett. 25 5377; (g) Felber H, Kresze G, Braun H and Vasella A 1984 Tetrahedron Lett. 25 5381

15. Kumar V and Kaushik M P 2005 Tetrahedron Lett. 46 8121

16. Wichterle O and Hudlicky M 1947 Collect. Czech. Chem. Commun. 12661

17. Gupta A K, Acharya J, Pardasani D and Dubey D K 2007 Tetrahedron Lett. 48767

18. (a) Mallya M N, Nagendrappa G, Prasad J S, Sridhar M A, Lokanath N K and Begum, N S 2001 Tetrahedron Lett. 42 2565; (b) Mallya M N and Nagendrappa G 2006 Arkivoc 155; (c) Kyung J H and Clapp L B 1976 J. Org. Chem. 41 2024; (d) Girija C R, Begum N S, Karim H A M A and Nagendrappa G 2004 Acta Cryst. E60 1764; (e) Kugelman M, Mallams A K and Vernay H F 1976 J. Chem. Soc. Perkin Trans. 1 1113; (f) Bozzi E G, Shiue Ch. Y and Clapp 
L B 1973 J. Org. Chem. 38 56; (g) We have used $\alpha$ chlorooximes to prepare $\alpha$-chloroketones under solventfree conditions, see Vimala B C and Nagendrappa G 2009 J. Chem. Sci. 1211011

19. Colonge J and Lartigau G 1965 Bull Soc. Chim. France. 738

20. Yakubovich A Ya, Shpanskii V A and Lemke A L 1954 Dokl. Akad. Nauk USSR 96 773; (b) Hass H B and Whitaker A C 1948 US Patent 2,447,504 (Chem. Abstr. 194943 3024i); (c) Mark V 1956 US Patent 2,771,470 (Chem. Abstr. 195751 6686)

21. (a) Spencer A N and Wain R L 1963 Ann. Appl. Biot. 51 153; (b) Mowry D T 1952 US Patent 2,591,589 (Chem. Abstr. 195448 11485)

22. (a) Bachman G B and Standish N W 1959 US Patent 2,999,118 (Chem. Abstr. 196256 2331d); (b) Nishimura T 1954 Bull. Chem. Soc. Jpn. 27617

23. Herzog L 1957 US Patent 3,000,933 (Chem. Abstr. 1962 56 1346a)

24. (a) Shechter H, Conrad F, Daulton A and Kaplan R 1952 J. Am. Chem. Soc. 74 3052; (b) Goddard D R 1958 J. Chem. Soc. 1955; (c) Schlubach H H and Braun A 1959 Ann Chem. 627 28; (d) Shin C, Yamaura M, Inui E, Ishida Y and Yoshimura J 1978 Bull. Chem. Soc. Jpn. 51 2618; (e) Bachmann G B and Chupp J P 1956 J. Org Chem. 21 465; (d) Bachmann G B and Hokama T 1960 J. Org. Chem. 25178

25. (a) Seebach D, Colvin E W, Lehr F and Weller T 1979 Chimia 31 1; (b) Rajappa S 1981 Tetrahedron 37 1453; (c) Barrett A G M and Graboskii G G 1986 Chem. Rev. 86 751; (d) Barrett A G M 1991 Chem. Soc. Rev. 20 95; (e) Perekalin V V, Lipina E S, Berestovitskaya V M and Effremov D A 1994 Nitroalkenes: Conjugated Nitro Compounds (New York: John Wiley); (f) Michael J P and Blom N F 1989 J. Chem. Soc. Perkin Trans 1 623; (g) Clive D L J, Bo Y, Tao Y, Daigneault S, Wu Y J and Meignan G 1996 J. Am. Chem. Soc. 118 4904; (h) Trost B M and Hitce J 2009 J. Am. Chem. Soc. 131 4572; (i) Watanabe N, Ikagawa A, Wang H, Murata K and Ikariya T 2004 J. Am. Chem. Soc. 126 11148; (j) Pansare S V and Pandya K 2006 J. Am. Chem. Soc. 128 9624; (k) Yoshida M, Sato A and Hara S 2010 Org. Biomol. Chem. 8 3031; Palomo C, Vera S, Mielgo A and G_mez-Bengoa 2006 Angew. Chem. Int. Ed. 45 5984; (1) Wiesner M, Revell J D and Wennemers H 2008 Angew. Chem. Int. Ed. 47 7539; (m) Rasappan R and Reiser O 2009 Eur. J. Org. Chem. 1305; (n) Luo J, Xu L W, Hay R A S and Lu Y X 2009 Org. Lett. 11 437; (o) Alcaine A, Marques-Lopez E, Merino P Tejero T and Herrera R P 2011 Org. Biomol. Chem. 9 2777; (p) Williams D R, Cullen Klein J and Chow N S C 2011 Tetrahedron Lett. 522120

26. (a) Ogloblin K A, Grigorova T H and Potekhin A A 1969 Zh. Org. Khim. 5 1360; (b) Khristov V Kh, Angelov Kh M, Petrov A A 1991 Russ. Chem. Rev. 60 39; (c)
Ogloblin A A and Samartsev M A 1964 Zhur. Obshch. Khim. 341530

27. (a) Closs G L and Brois S I $1960 \mathrm{~J}$. Am. Chem. Soc. 82 6068; (b) Tanabe K and Hayashi R 1962 Chem. Pharm. Bull. Japan 10 1177; (c) Leminer R U, Nagabhushan T L and Neill I K O 1964 Tetrahedron Lett. 1909; (d) Serfortein W J, Jordan J H and White J I 1964 Tetrahedron Lett. 1069; (e) Hassner A and Heathcock C 1964 J. Org. Chem. 29 1350; (f) Ponder B W and Walker D P 1967 J. Org. Chem. 32 4136; (g) Paul P 1993 Polyhedron 12 2057; (h) Chaudhury P K; Barbaruah M and Sharma P P 1994 Indian J. Chem. 33B 71; (i) Meinwald J, Meinwald Y C and Baker T N 1963 J. Am. Chem. Soc. 85 2513; (j) Beier T, Hauthal H G and Pritzkow 1964 J. Prakt. Chem. 26 304; (k) Freeman F 1975 Chem. Rev. 75 471; (1) Gowenlock B G and Richter-Addo G B 2004 Chem. Rev. 104 3315; (m) Boyer H J 1969 The chemistry of nitro and nitroso groups (eds) H Feuer and S Patai (New York: Interscience) part 1; (n) Glaser R, Murmann R K and Barnes C L 1996 J. Org. Chem. 61 1047; (o) Chow Y L, Pallay K S and Richard R 1979 Can. J. Chem. 57 2923; (p) Nelson D J 1999 Tetrahedron Lett. 40 5823; (q) Kadzyauskas P P and Zefirov N S 1968 Russ. Chem. Rev. 37543

28. (a) Bhusan V, Rathore $\mathrm{R}$ and Chandrasekaran $\mathrm{S}$ 1984 Synthesis 431; (b) Freeman F and Kappos J C 1989 J. Org. Chem. 54 2730; (c) Mallya M N and Nagendrappa G 1999 Synthesis 37; (d) Mallya M N and Nagendrappa G 2001 J. Chem. Soc. Perkin Trans. 2 1099; (e) Begum N S, Girija C R, Mallya M N and Nagendrappa G 2005 J. Mol. Struct. 229 31; (f) Bickley J F, Gilchrist T L and Mendonca R 2002 Arkivoc 192; (g) Rathore R, Vankar P S and Chandrasekaran S 1986 Tetrahedron Lett. 27 4079; (h) Vankar P S, Rathore R and Chandrasekaran S 1987 Synth. Commun. 17 195; (i) Holba V and Sumichrast R 1995 Monats. Chem. 126 681; (j) Shukla R, Sharma P K, Kotai L and Banerji K L 2003 Proc. Indian Acad. Sci. (J. Chem. Sci.) 115 129; (k) Vankar P S, Rathore R and Chandrasekaran S 1986 J. Org. Chem. 513063

29. (a) Vimala B C $2004 \mathrm{Ph}$ D Thesis Bangalore University; (b) Vimala B C and Nagendrappa G 2009 Saudi J. Chem. 13 169; (c) Sahu S, Patel S and Mishra B K 2005 Synth. Commun. 35 3123; (d) Patel S and Mishra B K 2007 Tetrahedron 63 4367; (e) Patel S and Mishra B K 2006 J. Org. Chem. 71 3522; (f) Patel S and Mishra B K 2004 Tetrahedron Lett. 451371

30. Furniss B S, Hannaford A J, Smith P W G and Tatchell A R 2004 Vogel's textbook of practical organic chemistry (Singapore: Pearson Education) $5^{\text {th }}$ edn, (a) p. 1019 ; (b) p. 1259 ; (c) p. 413

31. (a) Brand J C D and Stevens I D R 1958 J. Chem. Soc. 629; (b) Chauvet F, Heumann A and Waegell B 1987 J. Org. Chem. 1916; (c) Ogloblin K A 1964 Zh. Obsh. Khim. 34170 